\title{
A Tandem Repeat in Decay Accelerating Factor 1 Is Associated with Severity of Murine Mercury-Induced Autoimmunity
}

\author{
David M. Cauvi, ${ }^{1}$ Rodney Gabriel, ${ }^{2}$ Dwight H. Kono, ${ }^{3}$ \\ Per Hultman, ${ }^{4}$ and K. Michael Pollard ${ }^{2}$ \\ ${ }^{1}$ Department of Surgery, University of California, San Diego, 9500 Gilman Drive, No. 0739, La Jolla, CA 92093-0739, USA \\ ${ }^{2}$ Department of Molecular and Experimental Medicine, The Scripps Research Institute, La Jolla, CA 92037, USA \\ ${ }^{3}$ Department of Immunology and Microbial Science, The Scripps Research Institute, La Jolla, CA 92037, USA \\ ${ }^{4}$ Molecular and Immunological Pathology, Department of Experimental and Clinical Medicine, Linköping University, \\ 58183 Linköping, Sweden
}

Correspondence should be addressed to K. Michael Pollard; mpollard@scripps.edu

Received 4 January 2014; Accepted 21 February 2014; Published 10 April 2014

Academic Editor: Aristo Vojdani

Copyright () 2014 David M. Cauvi et al. This is an open access article distributed under the Creative Commons Attribution License, which permits unrestricted use, distribution, and reproduction in any medium, provided the original work is properly cited.

Decay accelerating factor (DAF), a complement-regulatory protein, protects cells from bystander complement-mediated lysis and negatively regulates T cells. Reduced expression of DAF occurs in several systemic autoimmune diseases including systemic lupus erythematosus, and DAF deficiency exacerbates disease in several autoimmune models, including murine mercury-induced autoimmunity (mHgIA). Dafl, located within Hmrl, a chromosome 1 locus associated in DBA/2 mice with resistance to mHgIA, could be a candidate. Here we show that reduced Dafl transcription in lupus-prone mice was not associated with a reduction in the Dafl transcription factor SP1. Studies of NZB mice congenic for the mHgIA-resistant DBA/2 Hmrl locus suggested that Dafl expression was controlled by the host genome and not the Hmrl locus. A unique pentanucleotide repeat variant in the second intron of Daf1 in DBA/2 mice was identified and shown in F2 intercrosses to be associated with less severe disease; however, analysis of Hmrl congenics indicated that this most likely reflected the presence of autoimmunity-predisposing genetic variants within the Hmrl locus or that Dafl expression is mediated by the tandem repeat in epistasis with other genetic variants present in autoimmune-prone mice. These studies argue that the effect of DAF on autoimmunity is complex and may require multiple genetic elements.

\section{Introduction}

Decay accelerating factor (DAF [the gene and protein designations for decay accelerating factor in this paper are $D A F$ for the human gene and DAF for the human protein; the mouse genes are Dafl and Daf2 and corresponding proteins DAF1 and DAF2] or CD55) is a surface-expressed member of the complement-regulatory protein family that protects cells from attack by autologous complement proteins [1]. DAF inhibits the neoformation and accelerates the dissociation of preformed $\mathrm{C} 3 / \mathrm{C} 5$ convertase complexes generated by the classical and alternative pathways, thus blocking both complement split product activity and the formation of the membrane attack complex [2]. DAF is present on inflammatory cells and at sites of tissue inflammation where it most likely inhibits bystander complement-mediated cell lysis (13). In addition, recent studies suggest DAF regulates T cell activity [3-6].

In humans, DAF is a single gene on chromosome 1q32 encoding a glycosylphosphatidylinositol- (GPI-) anchored cell surface glycoprotein [7]. In contrast, mice have two tandem Daf genes positioned head-to-tail on chromosome 1 [8] with the GPI-linked Dafi (Daf-GPI) located $5^{\prime}$ to the transmembrane containing Daf2 (Daf-TM). Expression of DAF varies depending on tissue [9] and cell type [10] with DAF widely expressed on the surface of all major circulating blood cells and epithelial and endothelial cells $[11,12]$. Studies with Daf1 knockouts showed that absence of the GPI form results in the loss of DAF expression in most tissues, except testis and spleen where Daf2 is expressed $(27,28)$. In the 
spleen, DAF2 is expressed primarily in $\mathrm{CD}_{11 c^{+}}$dendritic cells (28). In human cells, DAF expression is modulated by cytokines such as IL-1, IL-6, TNF- $\alpha$, TGF- $\beta 1$, and IFN- $\gamma$ [1315], prostaglandin PGE2 [16], and tissue specific factors [17]. Although there is evidence that DAF mRNA stability can be affected by tissue specific factors [17] and inflammation [18], most studies suggest that expression is primarily modulated at transcription $[15-17,19,20]$. The human $D A F$ promoter has been identified, the transcription start site mapped, and regions of potential transcriptional regulation proposed $[10$, 21]. Analysis of the key transcriptional regulatory elements controlling basal expression of mouse Dafl showed that transcriptional activity requires the functional cooperation of two Spl-binding sites and is enhanced by the presence of a CREB site [22].

Evidence supports a protective role for DAF in autoimmunity $[6,23]$. Dafl deficient mice exhibit increased $\mathrm{CD} 4^{+}$ $\mathrm{T}$ cell proliferation and greater secretion of IFN- $\gamma$, IL-2, and IL-4 but reduced IL-10 [4]. Furthermore, DAF1 is reduced on $\mathrm{T}$ and $\mathrm{B}$ cells in autoimmune prone NZB mice [24], and its deletion in lupus prone MRL-Fas ${ }^{l p r}$ mice accelerates disease [25]. During induction of murine mercury-induced autoimmunity (mHgIA) DAF1 is specifically reduced on $\mathrm{CD}^{+} \mathrm{T}$ cells resulting in an accumulation of activated $\left(\mathrm{CD} 44^{\text {high }} \mathrm{Daf}^{\text {low }}\right) \mathrm{CD}^{+}{ }^{+} \mathrm{T}$ cells [24]. Daf1 deficiency also exacerbates mHgIA via increased levels of IFN- $\gamma$, IL-2, IL4 , and IL-10 but not IL-17 [26]. DAF mediated complement regulation does not appear to contribute to mHgIA as neither the accumulation of $\mathrm{CD} 44^{\text {high }} \mathrm{Daf}^{\text {dow }} \mathrm{CD} 4^{+} \mathrm{T}$ cells nor the downregulation of DAF1 expression on $\mathrm{CD}^{+} \mathrm{T}$ cells was influenced by a lack of C3 [27]. Additionally, Dafl deficiency exacerbates organ specific disease in models of experimental autoimmune encephalomyelitis (EAE) [4], glomerulonephritis in antibody-induced nephritis [28, 29], and experimental myasthenia gravis [30]. Thus DAF impacts the expression of disease in both idiopathic and induced models of autoimmunity.

In a previous study, we showed that resistance to mHgIA resides at a single major quantitative trait locus on chromosome 1, designated Hmrl, which was shown to be linked to glomerular immune complex deposits but not autoantibody production [31]. Hmrl encompasses a region containing several lupus susceptibility loci as well as Daf1 and Daf2. As DAF regulates complement activation it is possible that differences in DAF expression may impact the deposition of immune complex deposits and contribute significantly to the Hmrl phenotype. In this study, we show that Dafl expression is reduced in multiple murine strains susceptible to spontaneous autoimmunity and identified a pentanucleotide tandem repeat in the second intron of Dafl, which in the mHgIA resistant DBA/2 consisted of eleven repeats while most other strains had 10, except for MRL-Fas ${ }^{l p r}$ and SJL/J, which lacked the repeat. Comparison of the presence or absence of the tandem repeat, in a (DBA/2xSJL/J)F2 intercross, with several disease parameters showed that presence of the DBA/2 repeat was associated with less severe disease. Analysis of NZB mice congenic for the Hmrl locus of DBA/2, however, showed that Daf1 expression is controlled by trans elements not within
$H m r l$ and the reduction in Dafl expression was not associated with changes in levels of its major transcription factor SP1. These studies document lower levels of Dafl in lupus-prone mice and show that this is not directly caused by cis elements within the Dafl gene or by differences in constitutive Sp1 expression.

\section{Materials and Methods}

2.1. Mice. $\mathrm{DBA} / 2, \mathrm{NZB}, \mathrm{MRL} / \mathrm{Fas}^{\mathrm{lpr}} / \mathrm{J}, \mathrm{BXSB}$, and C57BL/6 mice were obtained from the Scripps Research Institute Breeding Colony (La Jolla, CA). NZW/LacJ, A.SW/SnJ, $\mathrm{BALB} / \mathrm{cJ}, \mathrm{SJL} / \mathrm{J}$, and $129 \mathrm{~S} 6$ mice were obtained from the Jackson Laboratory (Bar Harbor, ME). (SJL/JxDBA/2)F2 intercross mice have been previously described [31]. NZB.DBA/2$\operatorname{Hmrl}\left(\operatorname{Daf} 1^{\mathrm{DBA} / 2}\right)$ and DBA/2.NZB-Hmrl(Daf $\left.1^{\mathrm{NZB}}\right)$ interval congenic mice that contained the relevant Daf1 locus were generated by marker-assisted breeding using D1Mit21 $(67 \mathrm{Mb})$ and D1Mit17 $(190 \mathrm{Mb})$ to define the outer limits of the chromosome 1 interval. Breeding and maintenance were performed under specific pathogen-free conditions at the Scripps Research Institute Animal Facility (La Jolla, CA). All procedures were approved by the Scripps Research Institute's Institutional Animal Care and Use Committee.

\subsection{RNA Isolation and Real-Time PCR. Total RNA extraction} from splenocytes was performed using TRIzol reagent (Invitrogen, Carlsbad, CA). RNA was denatured at $65^{\circ} \mathrm{C}$ for 5 minutes, placed on ice, and reverse transcribed in a total volume of $20 \mathrm{ml}$ using random hexamers, dNTPs, RNase inhibitor (RNase-OUT; Invitrogen), and 200 units of SuperScript III reverse transcriptase (Invitrogen). Real time PCR primers, probes, and methods were as previously described [24]. Daf1 was expressed relative to cyclophilin A or 18sRNA [24]. Levels of Sp1, Sp3, CREB, and CREM mRNA were determined in spleen cells of naïve female autoimmune prone NZB and healthy DBA/2 mice by real time PCR using iQ SYBR green Supermix (Bio-rad, Hercules, CA). The following primers were used for amplification: Spl forward, $5^{\prime}$-CAAACACCCCAGGTGATCATGGAAC- $3^{\prime}$, and Sp1 reverse, $5^{\prime}$-CAGTGAGGGAAGAGCCTCAGGAG-3'; Sp3 forward, $5^{\prime}$-GGCAGCTCAGTGGTGACTCTAC- $3^{\prime}$, and Sp3 reverse, $5^{\prime}$-GGTGGTGGGAGAGGTACCAATC-3'; CREB forward, $5^{\prime}$-GTGGGCAGTACATTGCCATTACCC-3', and CREB reverse, $5^{\prime}$-GTTGTTCAAGCTGCCTCAGGCG-3'; CREM forward, $5^{\prime}$-CACAGGTGACATGCCAACTTACCAG- ${ }^{\prime}$, and CREM reverse, $5^{\prime}$-CGGGAGTGTCGCAGGAAGAAG- ${ }^{\prime}$. All PCR reactions were performed using an iCycler iQ (Bio-Rad). The reactions were run in duplicate and relative expression mRNA levels were determined by the $\Delta \Delta C T$ method and normalized against cyclophilin A. Data are expressed as fold change compared to mRNA levels measured in DBA/2 samples.

2.3. Genomic DNA. Genomic DNA was isolated from $5 \mathrm{~mm}$ sections of mouse tail incubated in $500 \mu \mathrm{L}$ lysis buffer $(0.1 \mathrm{M}$ Tris, $\mathrm{pH} 8.0 ; 5 \mathrm{mM}$ EDTA; $0.2 \mathrm{M} \mathrm{NaCl}$ and $0.4 \% \mathrm{w} / \mathrm{v}$ SDS) containing $200 \mu \mathrm{g} / \mathrm{mL}$ proteinase K (Sigma, St Louis, MO) 
overnight at $55^{\circ} \mathrm{C}$. Samples were spun down and supernatants containing genomic DNA were purified using the ZR Genomic DNA ${ }^{\mathrm{TM}}$-Tissue MiniPrep kit (Zymo Research, Irvine, CA) according to the manufacturer's protocol.

2.4. Tandem Repeat PCR. The tandem repeat sequence, which can be represented by either (CTTTT)n or (TTTTC)n, was identified within the second intron of Daf1 using the following primers: $5^{\prime}$-GCTTAAGGCATTACTGTCTGC-3' (forward) and $5^{\prime}$-GCCATCCTAATGTAAAGTAACTCC-3' (reverse). PCR amplifications were performed with the KOD Hot Start Polymerase (EMD Millipore, Billerica, MA) using the following conditions: an initial 2 min denaturation step at $94^{\circ} \mathrm{C}$ and then 35 cycles of denaturation $\left(94^{\circ} \mathrm{C}\right)$, annealing $\left(57^{\circ} \mathrm{C}\right)$, and extension $\left(68^{\circ} \mathrm{C}\right)$ followed by a final $10 \mathrm{~min}$ $68^{\circ} \mathrm{C}$ incubation step. The PCR products were separated by agarose gel electrophoresis, extracted using the QIAquick Gel Extraction Kit (Qiagen, Valencia, CA), and submitted for sequencing.

2.5. DNA Sequencing. Purified PCR products were submitted to the Scripps Research Institute DNA Core Facility and analyzed with an ABI PRISM 3100 sequencer using appropriate primers. Sequencing data were analyzed with the BioEdit Sequence Alignment Editor software.

2.6. Induction and Assessment of $m H g I A$ in (SJL/JxDBA/2)F2 Intercross Mice. Induction and features of mHgIA including immune deposits in kidney and spleen and serum autoantibodies and MHC class II genotypes in (SJL/JxDBA/2)F2 intercross mice were described previously [31]. Use of mercuric chloride was approved by the Scripps Research Institute Department of Environmental Health and Safety.

2.7. Statistics. Unless otherwise noted, all data is expressed as mean and standard error. Statistical analysis was done using GraphPad Software, San Diego, CA. Mann-Whitney $U$ test was used for comparisons between individual mouse strains. Analysis of variance (ANOVA) with Bonferroni's Multiple Comparison test was used for comparisons between features of mHgIA in (SJL/JxDBA/2)F2 intercross mice. $P<0.05$ was considered significant.

\section{Results}

3.1. Daf1 mRNA Expression is Reduced in Autoimmune Prone Mice. In a previous study, we found that autoimmune prone NZB mice have reduced endogenous DAF1 expression [24]. To determine if this is common to other lupus-prone strains we analyzed Daf1 mRNA expression in spleen cells from naïve female autoimmune prone MRL-Fas ${ }^{l p r}$ (MRL/lpr), NZB, NZW, and BXSB mice and healthy DBA/2 and BALB/c mice (Figure 1). All the autoimmune prone strains had lower Daf1 mRNA levels than the DBA/ 2 confirming that reduced DAF1 expression is coupled to a predisposition for autoimmunity. Daf1 expression in BALB/c mice was no different from $\mathrm{DBA} / 2$ but was higher than the other strains tested $(P<$ 0.01). Interestingly, SJL/J mice also had reduced Daf1 mRNA

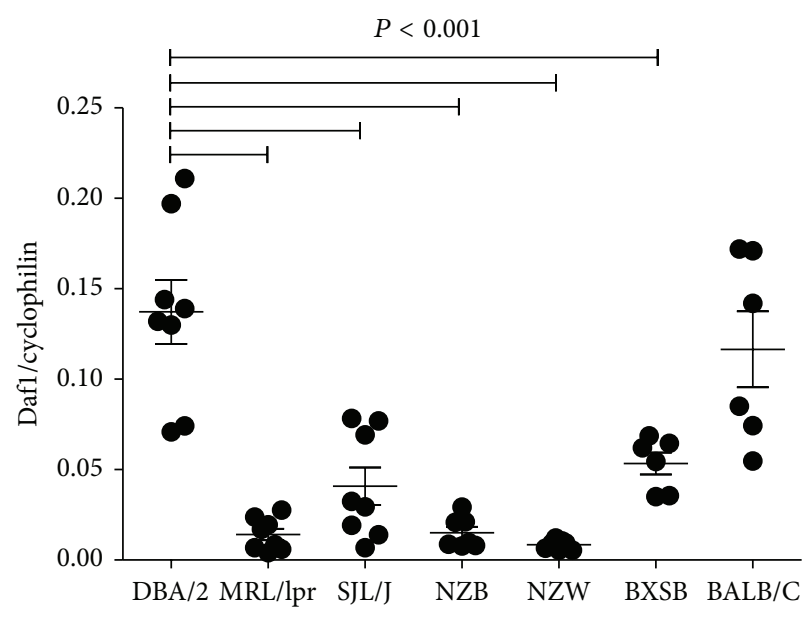

FIGURE 1: Daf1 mRNA is reduced in autoimmune prone mice. Real time PCR was used to determine Daf1 mRNA in spleen cells of naïve female autoimmune prone MRL-Fas ${ }^{l p r}$ (MRL/lpr), NZB, NZW, and BXSB mice and healthy DBA/2 and BALB/c mice. Daf1 was expressed relative to cyclophilin A. $N=4-5$ mice $/$ strain.

expression. This may reflect the propensity of SJL/J mice to develop autoimmunity with age [32] but may also be a manifestation of dysferlin deficiency in these mice [33]. Thus, Daf1 is reduced in strains with a predisposition to autoimmunity.

3.2. Intron 2 of Daf1 Contains a Pentanucleotide Tandem Repeat. Differences in expression of DAF1 might reflect genetic polymorphisms among the different strains. Sequencing of Daf1 transcripts and $2.5 \mathrm{~kb}$ of genomic DNA $5^{\prime}$ of the Daf1 ATG start site in NZB and DBA/2 mice revealed no differences compared to the C57BL/6 genome. However, further examination identified a tandem repeat in the second intron of Dafl (Figure 2). Sequencing of this region in a number of mouse strains revealed three different genotypes. $\mathrm{DBA} / 2$ mice had the longest repeat sequence with CTTTT (or TTTTC) being repeated 11 times. NZB, NZW, BXSB, B10.S, C57BL/6, A.SW/Sn, BALB/c, and 129 S6 mice had 10 repeats while MRL-Fas ${ }^{l p r}$ and SJL/J lacked the tandem repeat. Tandem repeat length did not show a strict correlation with Daf1 mRNA expression, although the longest repeat was found in the strain with the highest expression (DBA/2) while the two strains lacking the tandem repeat, MRL$\mathrm{Fas}^{l p r}$ and SJL/J, did have significantly lower expression than the DBA/2 (Figure 1). The inability of mercury exposure to decrease DAF1 expression in mHgIA resistant DBA/2 mice [24] suggested the possibility that the DBA/2 tandem repeat may influence the expression of Dafl and, in turn, the severity of autoimmunity.

3.3. Presence of the DBA/2 Daf1 Tandem Repeat Is Associated with Reduced Immune Deposits. To determine if the DBA/2 tandem repeat variant is associated with facets of mHgIA we examined archived DNA samples from 133 mice from a (SJL/JxDBA/2)F2 intercross which had been used to identify 


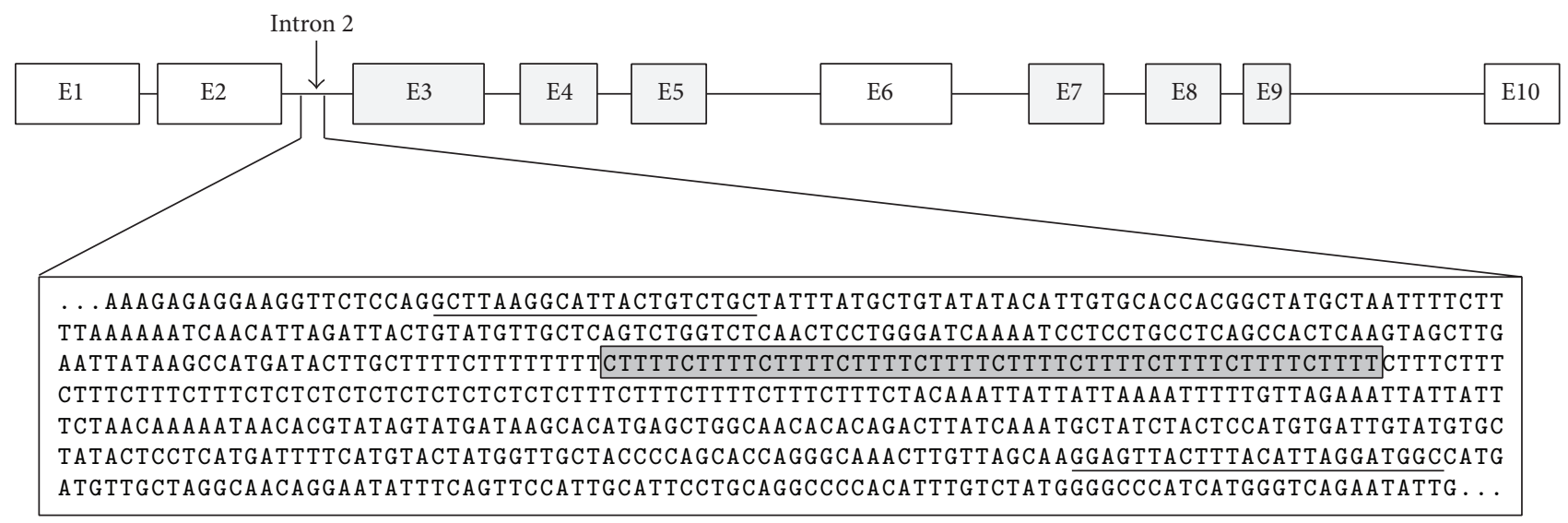

CTTTT (or TTTTC) repeat length

$11-\mathrm{DBA} / 2$

10-NZB, NZW, BXSB, B10.S, C57BL/6, A.SW/Sn, BALB/c, and 129 S6

$0-\mathrm{MRL}-\mathrm{Fas}^{\mathrm{lpr}}$ and SJL/J

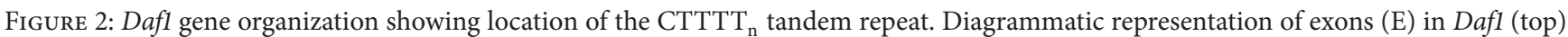
and the expanded region of sequence in intron 2 (bottom) showing the CTTTT tandem repeat (shaded box) and PCR primers sequences (underlined). DNA sequence is from the C57BL/6 genomic sequence which has ten CTTTT repeats. Note that the repeat can also be represented by TTTTC by simple removal of the $\mathrm{C}$ residue at the $5^{\prime}$ end and inclusion of the $\mathrm{C}$ at the $3^{\prime}$ end. DBA/ 2 mice had the longest repeat sequence with CTTTT (or TTTTC) being repeated 11 times. NZB, NZW, BXSB, B10.S, C57BL/6, A.SW/Sn, BALB/c, and 129S6 mice had 10 repeats while MRL-Fas ${ }^{l p r}$ and SJL/J lacked the repeat.

$\begin{array}{llllllllllllllllllllllll}1 & 2 & 3 & 4 & 5 & 6 & 7 & 8 & 9 & 10 & 11 & 12 & 13 & 14 & 15 & 16 & 17 & 18 & 19 & 20 & 21 & 22 & 23 & 24\end{array}$

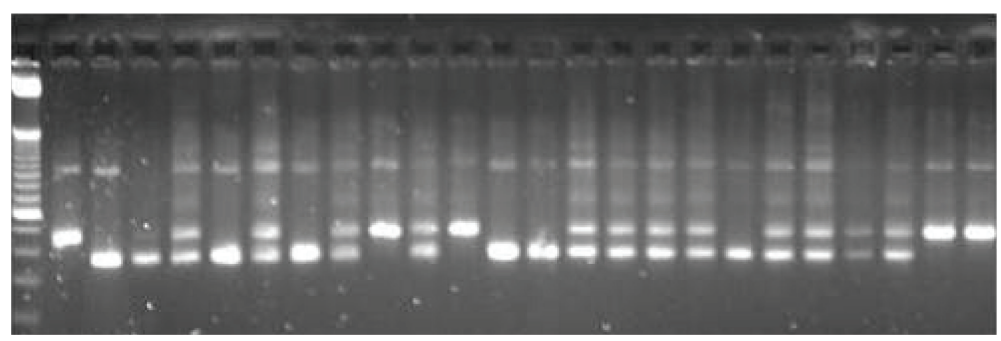

FIGURE 3: PCR determination of presence or absence of CTTTT tandem repeat. Archived DNA from mercury treated (SJL/JxDBA/2)F2 intercross mice was subjected to PCR using appropriate primers (see Figure 2) and products separated by agarose gel electrophoresis. Lane 1, base pair marker; lane 2, homozygous D tandem repeat; lanes 3 and 4, homozygous $\mathrm{S}$ tandem repeat; lane 5, heterozygous D/S tandem repeat; lanes 6-25, (SJL/JxDBA/2)F2.

the Hmrl locus [31]. PCR analysis determined that there were 32 mice with the DBA/2 (D/D) tandem repeat: 28 had the SJL/J (S/S) genotype as they lacked the tandem repeat and 73 were heterozygous (D/S) animals (Figure 3). Tandem repeat status was then compared to previously obtained data [31] of immune deposits in kidney and spleen and serum autoantibodies to determine the relationship between presence or absence of the tandem repeat and severity of mHgIA.

Comparison of autoantibody responses revealed that $\mathrm{D} / \mathrm{D}, \mathrm{S} / \mathrm{S}$, and $\mathrm{D} / \mathrm{S}$ tandem repeat groups showed no differences in antinucleolar autoantibody (ANoA) response but the antichromatin autoantibody (ACA) response was greater in $\mathrm{S} / \mathrm{S}$ than $\mathrm{D} / \mathrm{D}$ animals $(P<0.05)$ (Figure 4$)$. Comparison of immune deposits found that $\mathrm{D} / \mathrm{D}$ animals had reduced glomerular IgG deposits $(P<0.05)$ compared to $S / S$ animals but no differences were found for C3 deposits (Figure 4) or glomerular IgM. Immune deposits in the spleen were also affected by the presence of the $\mathrm{D} / \mathrm{D}$ tandem repeat with $\mathrm{D} / \mathrm{D}$ animals having reduced IgG and C3 deposits in splenic vessels compared to $\mathrm{S} / \mathrm{S}$ animals $(P<0.05)$ (Figure 4$)$. Splenic vessel deposits of C3 were also reduced in D/S animals compared to $\mathrm{S} / \mathrm{S}$ animals $(P<0.05)$. Of the 133 animals, 13 had $\mathrm{IgG}$ deposits in both kidney glomeruli and splenic vessels and of these $6(46 \%)$ were S/S, $5(38 \%) \mathrm{D} / \mathrm{S}$, and 2 (15\%) D/D. When expressed as a percentage of each genotype this revealed that $21 \%$ of the S/S mice had deposits in both organs, while only $7 \%$ of $\mathrm{D} / \mathrm{S}$ and $6 \%$ of $\mathrm{D} / \mathrm{D}$ had such deposits. None of 8 $\mathrm{DBA} / 2$ mice had deposits in either organ while 5/8 SJL/J had deposits with 4 of these having deposits in kidney and 


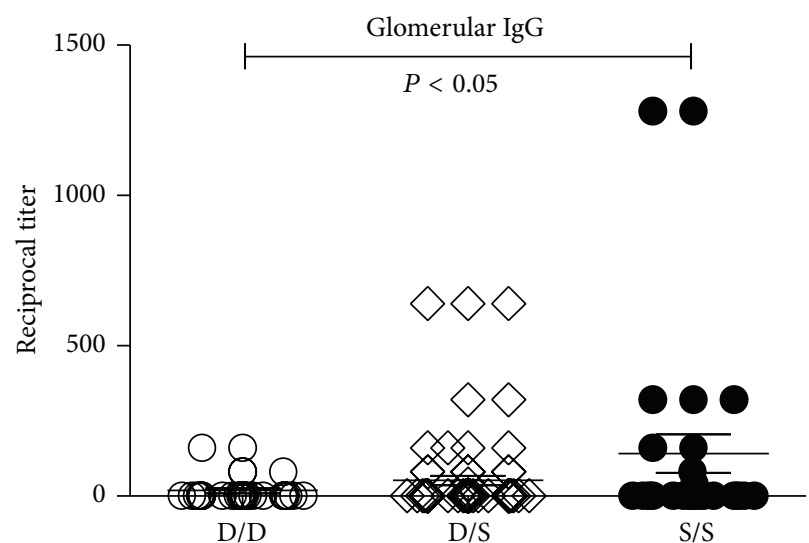

(a)

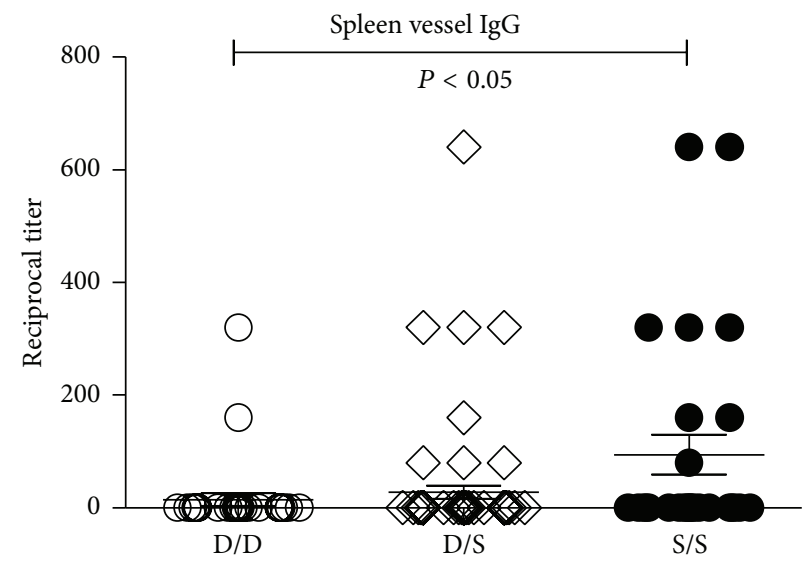

(c)

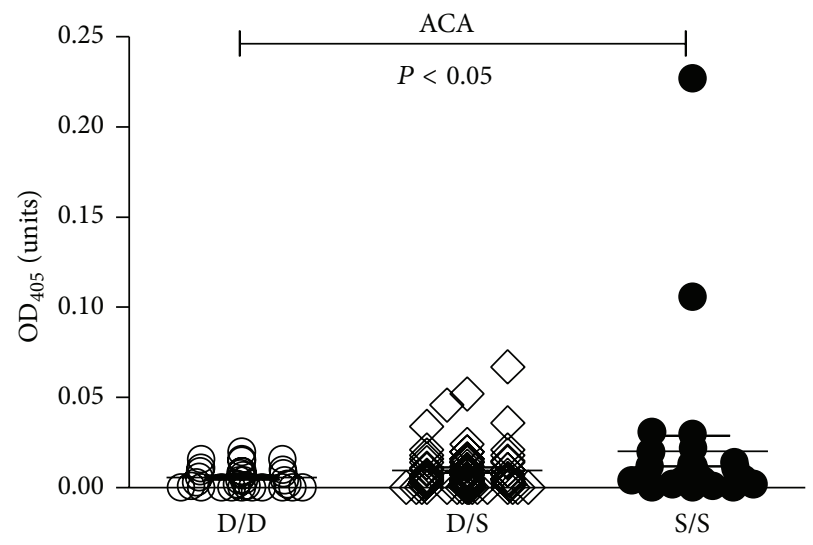

(e)

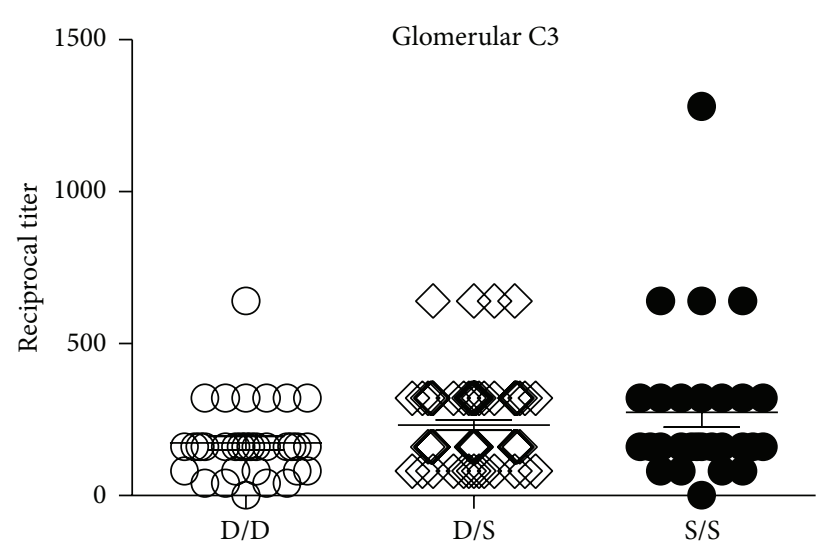

(b)

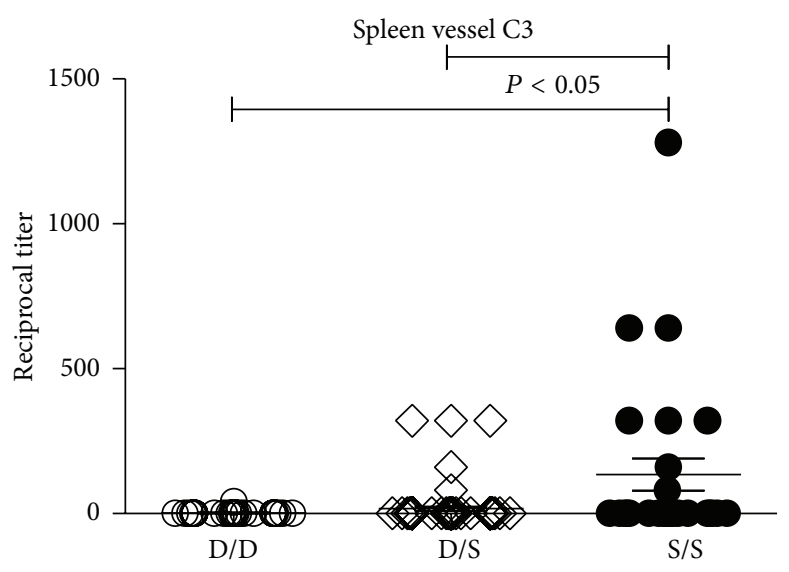

(d)

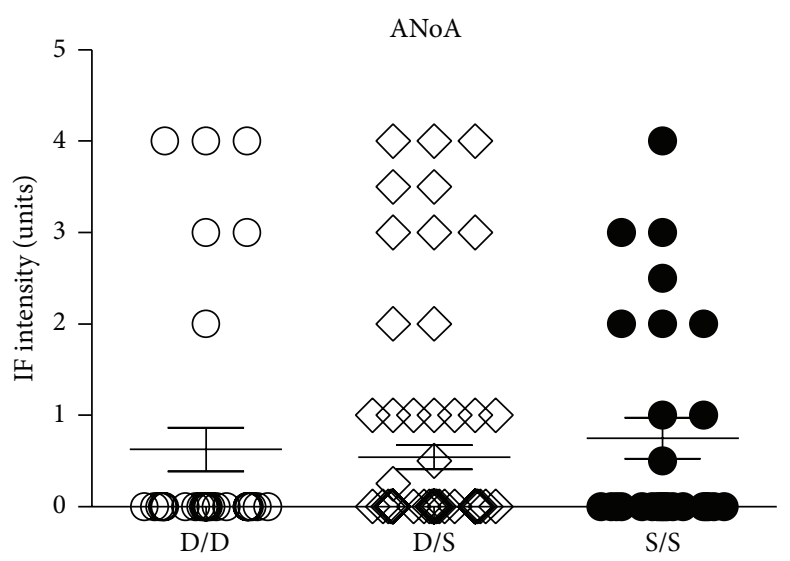

(f)

FIGURE 4: Presence of the DBA/2 tandem repeat is associated with reduced immune deposits. Tandem repeat genotypes (D/D, S/S D/S) were compared with features of mHgIA including glomerular deposits of IgG and C3, splenic vessel deposits of IgG and C3, antichromatin autoantibodies (ACA), and antinucleolar autoantibodies (ANoA) in 133 (SJL/JxDBA/2)F2 intercross mice.

spleen. These observations suggest that heterozygous and particularly homozygous presence of the D tandem repeat of Dafl is associated with less severe disease.

3.4. MHC Class II Genotype Is Not Associated with Reduced Immune Deposits. Autoimmunity, including mHgIA [31], is associated with class II genes of the MHC [34]. Therefore, differences in severity of mHgIA in the (SJL/JxDBA/2)F2 intercross could simply reflect distribution of DBA/2 and $\mathrm{SJL} / \mathrm{J} \mathrm{MHC}$ class II genes. To examine this possibility comparison was made between the MHC class II genotypes and the presence of immune deposits in kidney and spleen and serum 


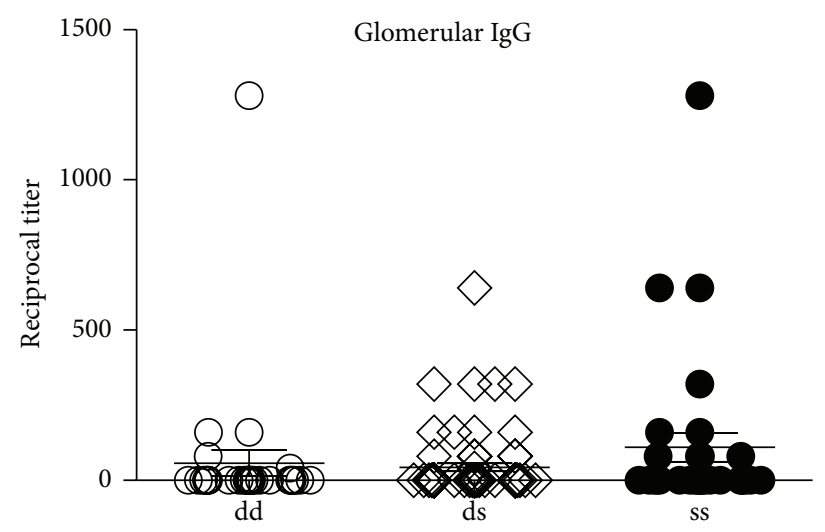

(a)

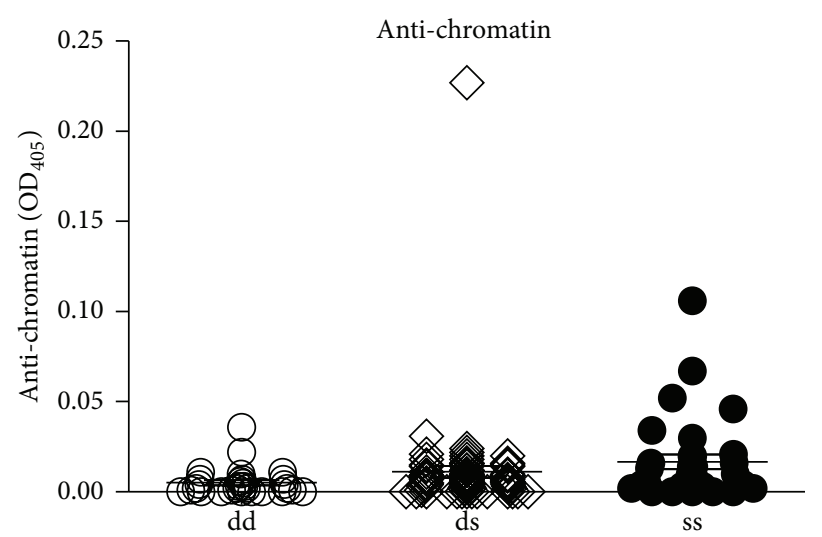

(c)

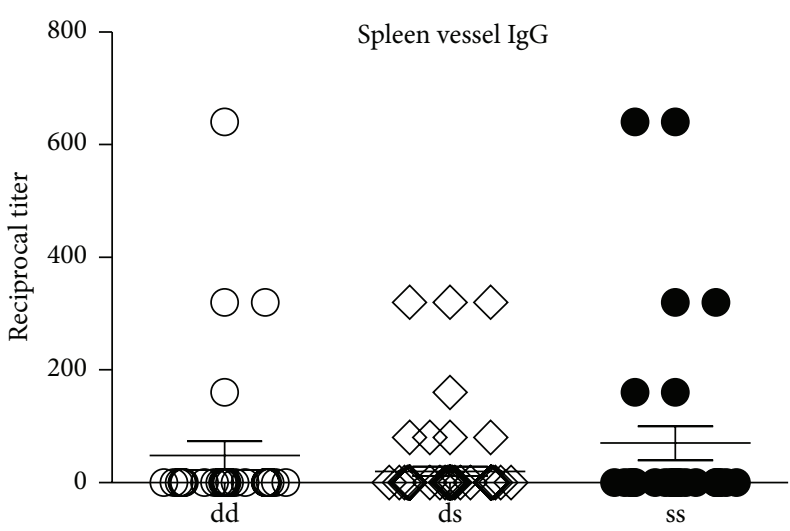

(b)

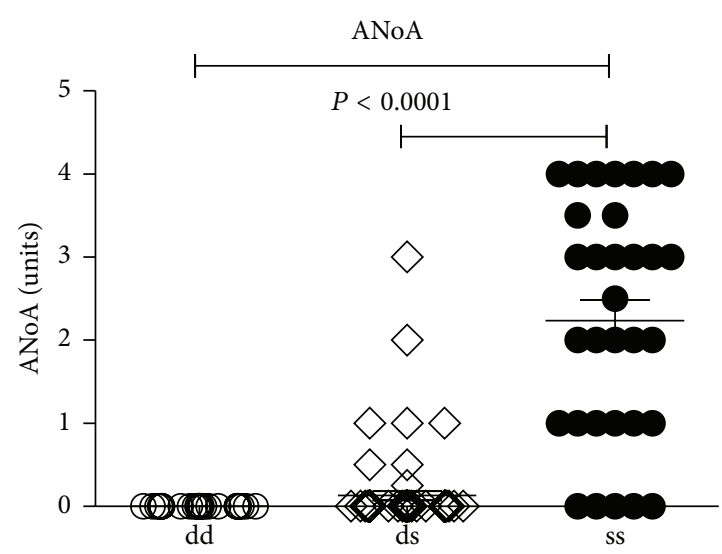

(d)

FIGURE 5: MHC class II is not associated with reduced immune deposits. MHC class II genotypes of (SJL/JxDBA/2)F2 intercross mice (H$2^{\mathrm{d}}$, dd $\mathrm{H}-2^{\mathrm{s}}$, ss $\mathrm{H}-2^{\mathrm{ds}}$, ds) were compared with features of mHgIA including glomerular deposits of IgG, splenic vessel deposits of IgG, antichromatin autoantibodies (ACA), and antinucleolar autoantibodies (ANoA). $N=133$.

autoantibodies. MHC class II was not associated deposits of IgG (Figure 5) or C3. Antichromatin autoantibodies were also not associated with MHC class II but, as described previously $[31,35]$, ANoA was highly associated with mice that were homozygous for $\mathrm{H}-2^{\mathrm{s}}(P<0.0001)$ (Figure 5). Therefore immune deposits do not reflect of the distribution of DBA/2 or SJL/J MHC.

3.5. Expression of Daf1 Is Not Regulated within the Hmr1 Locus. Strain specific differences in the expression of Daf1 [24] and the relationship of Hmrl to disease severity [31] suggested that transfer of the DBA/2 Hmr1 locus into autoimmune susceptible mice may help determine if Daf1 expression was controlled within the Hmrl locus. NZB mice made congenic for the DBA/2 Hmrl locus (NZB.DBA/2-Hmr1(Daf $\left.1^{\mathrm{DBA} / 2}\right)$ or ND) still had reduced Daf1 expression, while DBA/2 mice congenic for the NZB locus (DBA/2.NZB-Hmr $1\left(\operatorname{Daf} 1^{\mathrm{NZB}}\right)$ or $\left.\mathrm{DN}\right)$ retained the elevated expression of Daf1 (Figure 6). Thus, Daf1 expression is affected by genetic elements outside of the Hmrl locus.
3.6. Daf1 Transcription Factor Expression Is Not Reduced in Autoimmune Prone Mice. We previously determined that constitutive expression of Daf1 is under the control of the transcription factor SP1 [22] which suggested that the reduced expression of Daf1 in autoimmune prone mice may be due to reduced expression of Spl. Real time PCR analysis of $S p 1$ in splenocytes revealed increased expression in NZB compared to DBA/2 mice although Sp3, another member of the Spl family, showed no difference in expression (Figure 7). The Daf1 promoter also contains a CREB binding site [22], however expression of this transcription factor was not different between the two mouse strains although the closely related CREM was increased in NZB mice (Figure 7). Thus reduced Daf1 in NZB mice could not be attributed to the lack of putative transcription factors, including SP1.

\section{Discussion}

In this study, we extended our observation that lupus-prone NZB mice have reduced DAF1 [24] to other major lupus strains including MRL-Fas ${ }^{l p r}$, NZW, and BXSB mice. Thus, 


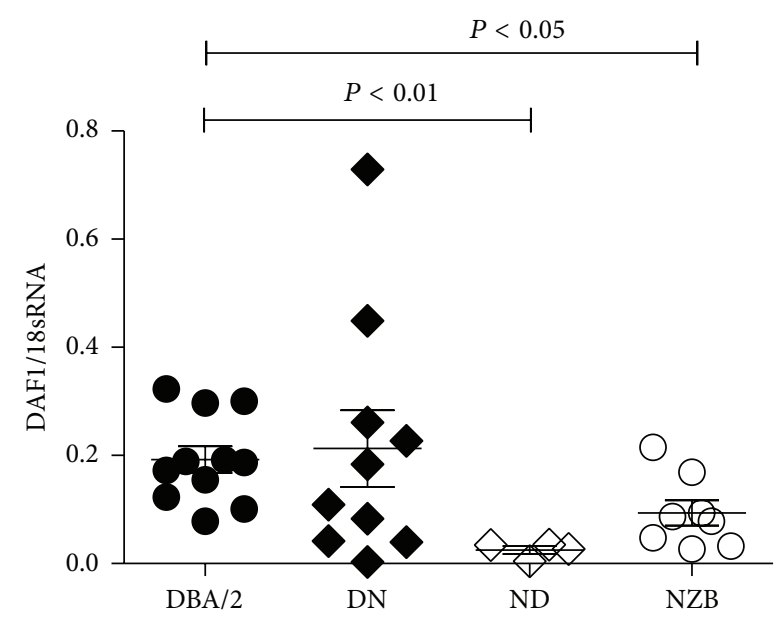

Figure 6: Hmrl locus does not control Dafl expression. NZB and DBA/2 mice were made congenic for the Hmrl locus and Daf1 expression determined from spleen cells. NZB.DBA/ $2-H m r 1\left(D a f 1^{\mathrm{DBA} / 2}\right)=\mathrm{ND} ; \mathrm{DBA} / 2 . \mathrm{NZB}-H m r 1\left(\operatorname{Daf} 1^{\mathrm{NZB}}\right)=$ $\mathrm{DN} ; N=4-11$.

reduction of DAF1 is closely associated with susceptibility to autoimmunity. Examination of the Daf1 sequence revealed a pentanucleotide tandem repeat of either $(\text { CTTTT })_{n}$ or (TTTTC) $)_{\mathrm{n}}$ in intron 2 , with DBA/2 mice having the most repeats while most other strains had one fewer repeat except for MRL-Fas ${ }^{l p r}$ and SJL/J mice, which completely lacked the repeat. These observations suggested that resistance of DBA/2 to mercury-induced DAF1 downregulation and subsequent mHgIA might be related to the presence of the longer tandem repeat. Comparison of the presence and absence of the tandem repeat with features of mHgIA supported this possibility by revealing that absence of the repeat was linked with more severe disease particularly IgG deposits. However, mice congenic for the Hmrl locus [31], which contains Dafl, demonstrated that presence of the DBA/2 tandem repeat in NZB mice and vice versa did not influence Daf1 expression. Furthermore, Dafl expression was not related to an increase in the transcription factor SP1 which has been shown to regulate constitutive expression of Dafi [22].

Several lines of evidence have previously suggested that Dafl is the most likely gene within the Hmrl to explain the association with glomerular immune complex deposits. First, gene expression profiling of NZB and DBA/2 mice exposed to mercury identified 12 differentially expressed genes within the Hmrl including Daf1 [36]. As expected, Daf1 had greater expression in mHgIA-resistant DBA/2 mice relative to the autoimmune-prone NZB. Moreover, Daf1 was the only gene with a functional activity, inhibition of complement activation, which offers an explanation for the phenotype displayed by the Hmr1 locus. Thus the biological role of DAF1 as a negative regulator of complement activation points to its association with deposition of immune complexes. Second, the DBA/2 mouse does not develop mHgIA $[31,37]$ and $\mathrm{Hg}$ exposure does not affect its expression of DAF1 [24]. Third, the SJL/J, which lacks the tandem repeat, has significantly reduced Dafi [33], is highly susceptible to mHgIA, and develops significant immune deposits [37]. Our finding that mice congenic for the Hmrl do not display any difference in Dafl expression compared to their original strain suggests that the association of the absence of Dafl tandem repeat with immune deposits might simply reflect the presence of lupuspredisposing genetic variants within the Hmrl locus [31]. However, it is also possible that the Dafl-expression mediated by the tandem repeat is in epistasis with other genetic variants present in lupus mice.

Our previous studies showed that constitutive expression of Dafl is regulated by the transcription factor SP1 [22], but we were unable to demonstrate a correlation of constitutive Sp1 expression with DAF1 levels. Thus, the reduced expression of DAF1 in autoimmune-prone mice likely involves multiple factors. One intriguing possibility is that the TTTTC pentanucleotide sequence may contribute to Dafl expression as it has been identified as an IFN- $\gamma$ and IRF1 response element of the mouse RANTES promoter [38], both IFN- $\gamma$ and IRF1 are required for mHgIA [39], and deficiency of Dafl is associated with increased IFN- $\gamma$ [4]. It can be speculated that the lack the pentanucleotide repeat in lupus-prone MRL-Fas ${ }^{l p r}$ and the mHgIA-sensitive SJL/J might reduce IRF1s influence on Daf1 transcription. This is supported by the observation that mice deficient in IFN- $\gamma$ or IRF1 have reduced DAF1 on activated $\mathrm{CD} 4^{+} \mathrm{T}$ cells following mercury exposure even though they do not develop mHgIA [39]. Other mice that are sensitive to mHgIA, such as the B10.S, do have the tandem repeat, and naive mice have approximately equivalent DAF1 on $\mathrm{CD} 4^{+} \mathrm{T}$ cells as DBA/2 mice [24]. However, induction of mHgIA in the B10.S results in a reduction of DAF1 to levels found in naive NZB while DBA/2 are unaffected [24]. This suggests the possibility that the presence of an additional cis-acting element in the DBA/2 is even more efficient at maintaining Daf1 expression.

Although the role of the tandem repeat sequence, (CTTTT)n or (TTTTC)n, in Daf1 expression and mHgIA remains to be resolved, similar sequences in other genes have been shown to influence biological responses. CTTTT or TTTTC repeats have been found in human HLA [40], the CD4 locus [41], and the murine RANTES promoter [38]. The repeat at the CD4 locus has been associated with type I diabetes [42] and vitiligo [43]. A similar sequence, (CCTTT)n, has been found in the promoter of human inducible nitric oxide synthase (NOS2A) where 14 repeats are associated with absence of diabetic retinopathy [44]. IL-1 $\beta$ induction of NOS2A with 9,12 , or 15 repeats was inhibited by the presence of $25 \mathrm{mM}$ glucose while the 14 repeats maintained transcription. Whether the size of the tandem repeat influences Dafl promoter activity in idiopathic and/or mercury-induced autoimmunity remains to be determined.

\section{Conclusions}

These studies show that expression of decay accelerating factor 1 is reduced in mice susceptible to systemic autoimmunity. Control of Dafl expression appears to be multifactorial and is not primarily mediated by a pentanucleotide tandem repeat 
$\mathrm{Sp} 1$

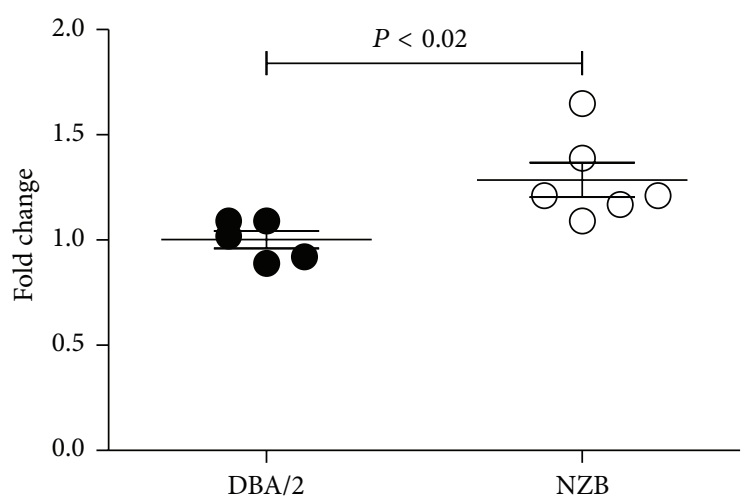

(a)

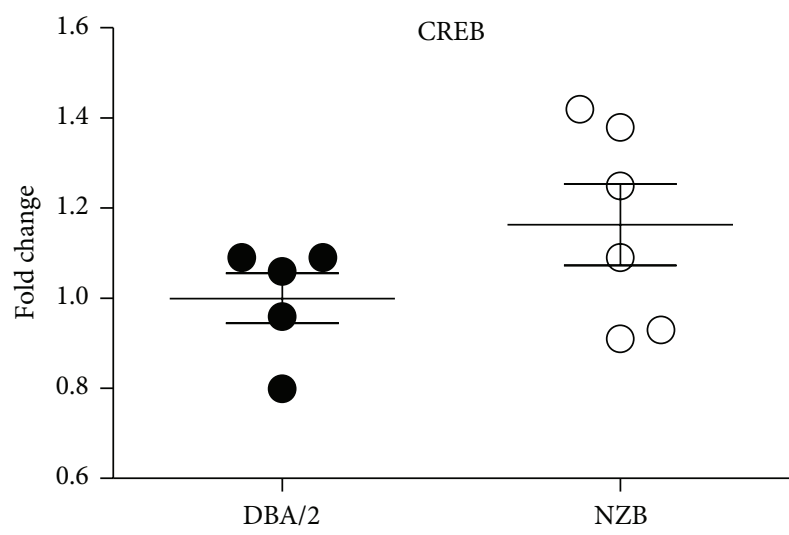

(c)
Sp3

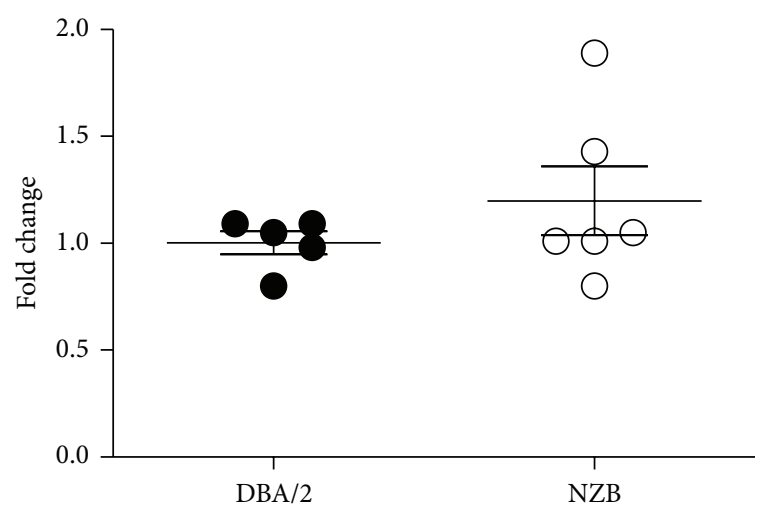

(b)

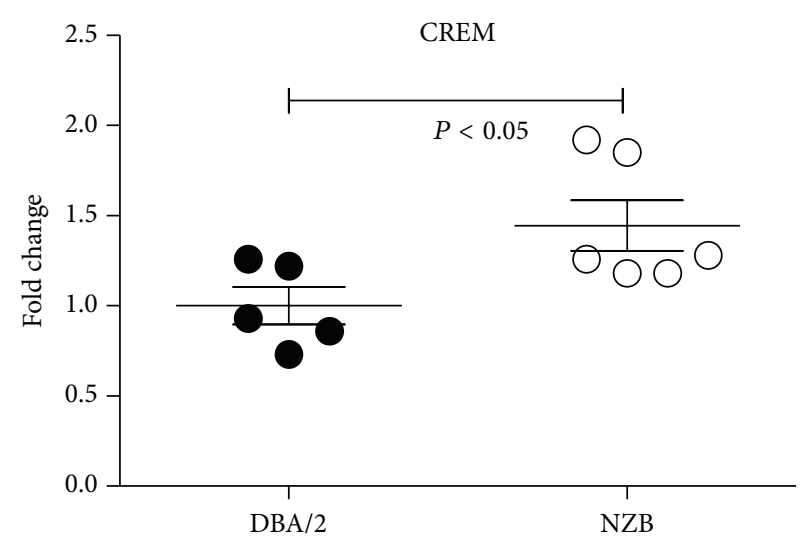

(d)

FIGURE 7: Daf1 transcription factor expression is not reduced in autoimmune prone mice Real time PCR was used to determine Sp1, Sp3, $C R E B$, and CREM mRNA in spleen cells of naïve female autoimmune prone NZB and healthy DBA/2 mice. mRNA levels were determined by the $\triangle \triangle \mathrm{CT}$ method and normalized against cyclophilin A. Data are expressed as fold change compared to mRNA levels measured in DBA/2 samples. $N=5 \mathrm{DBA} / 2$ and $6 \mathrm{NZB}$.

in intron 2 nor constitutive differences in SP1 expression. The absence of the tandem repeat was associated with increased severity of immune deposits in mercury-induced autoimmunity, which may be due to linkage of the repeat with other predisposing variants or epistasis with other genes that promote Daf1 expression.

\section{Conflict of Interests}

The authors report no conflict of interests.

\section{Acknowledgment}

This work was supported by NIH Grants ES014847, ES020388, ES021464 (KMP), ES08666, and AR053731 (DHK).

\section{References}

[1] D. M. Lublin and J. P. Atkinson, "Decay-accelerating factor: biochemistry, molecular biology, and function," Annual Review of Immunology, vol. 7, pp. 35-58, 1989.
[2] W.-C. Song, "Membrane complement regulatory proteins in autoimmune and inflammatory tissue injury," Current Directions in Autoimmunity, vol. 7, pp. 181-199, 2004.

[3] P. S. Heeger, P. N. Lalli, F. Lin et al., "Decay-accelerating factor modulates induction of $\mathrm{T}$ cell immunity," Journal of Experimental Medicine, vol. 201, no. 10, pp. 1523-1530, 2005.

[4] J. Liu, T. Miwa, B. Hilliard et al., "The complement inhibitory protein DAF (CD55) suppresses T cell immunity in vivo," Journal of Experimental Medicine, vol. 201, no. 4, pp. 567-577, 2005.

[5] M. P. Longhi, C. L. Harris, B. P. Morgan, and A. Gallimore, "Holding T cells in check-a new role for complement regulators?” Trends in Immunology, vol. 27, no. 2, pp. 102-108, 2006.

[6] W.-C. Song, "Complement regulatory proteins and autoimmunity," Autoimmunity, vol. 39, no. 5, pp. 403-410, 2006.

[7] T. W. Post, M. A. Arce, M. K. Liszewski, E. S. Thompson, J. P. Atkinson, and D. M. Lublin, "Structure of the gene for human complement protein decay accelerating factor," Journal of Immunology, vol. 144, no. 2, pp. 740-744, 1990.

[8] A. P. Spicer, M. F. Seldin, and S. J. Gendler, "Molecular cloning and chromosomal localization of the mouse decayaccelerating factor genes: duplicated genes encode 
glycosylphosphatidylinositol-anchored and transmembrane forms," Journal of Immunology, vol. 155, no. 6, pp. 3079-3091, 1995.

[9] F. Lin, Y. Fukuoka, A. Spicer et al., "Tissue distribution of products of the mouse decay-accelerating factor (DAF) genes. Exploitation of a Dafl knock-out mouse and site-specific monoclonal antibodies," Immunology, vol. 104, no. 2, pp. 215$225,2001$.

[10] D. J. Thomas and D. M. Lublin, "Identification of 5 '-flanking regions affecting the expression of the human decay accelerating factor gene and their role in tissue-specific expression," Journal of Immunology, vol. 150, no. 1, pp. 151-160, 1993.

[11] A. Nicholson-Weller, J. P. March, and C. E. Rosen, "Surface membrane expression by human blood leukocytes and platelets of decay-accelerating factor, a regulatory protein of the complement system," Blood, vol. 65, no. 5, pp. 1237-1244, 1985.

[12] M. E. Medof, E. I. Walter, and J. L. Rutgers, "Identification of the complement decay-accelerating factor (DAF) on epithelium and glandular cells and in body fluids," Journal of Experimental Medicine, vol. 165, no. 3, pp. 848-864, 1987.

[13] O. B. Spiller, O. Criado-Garcia, S. Rodriguez de Cordoba, and B. P. Morgan, "Cytokine-mediated up-regulation of CD55 and CD59 protects human hepatoma cells from complement attack," Clinical and Experimental Immunology, vol. 121, no. 2, pp. 234241, 2000.

[14] E. T. Cocuzzi, D. Bardenstyein, A. Stavitsky, N. Sudarraj, and M. E. Medof, "Upregulation of DAF (CD55) on orbital fibroblasts by cytokines. Differential effects of TNF- $\beta$ and TNF- $\alpha$," Current Eye Research, vol. 23, no. 2, pp. 86-92, 2001.

[15] S. R. Ahmad, E. A. Lidington, R. Ohta et al., "Decay-accelerating factor induction by tumour necrosis factor- $\alpha$, through a phosphatidylinositol-3 kinase and protein kinase C-dependent pathway, protects murine vascular endothelial cells against complement deposition," Immunology, vol. 110, no. 2, pp. 258268, 2003.

[16] V. R. Holla, D. Wang, J. R. Brown, J. R. Mann, S. Katkuri, and R. N. DuBois, "Prostaglandin E2 regulates the complement inhibitor CD55/decay-accelerating factor in colorectal cancer," Journal of Biological Chemistry, vol. 280, no. 1, pp. 476-483, 2005.

[17] A. Andoh, K. Kinoshita, I. Rosenberg, and D. K. Podolsky, "Intestinal trefoil factor induces decay-accelerating factor expression and enhances the protective activities against complement activation in intestinal epithelial cells," Journal of Immunology, vol. 167, no. 7, pp. 3887-3893, 2001.

[18] J. Saklatvala, J. Dean, and A. Clark, "Control of the expression of inflammatory response genes," Biochemical Society Symposium, no. 70, pp. 95-106, 2003.

[19] G. Kendall, H. Crankson, E. Ensor et al., "Activation of the gene encoding decay accelerating factor following nerve growth factor treatment of sensory neurons is mediated by promoter sequences within 206 bases of the transcriptional start site," Journal of Neuroscience Research, vol. 45, no. 2, pp. 96-103, 1996.

[20] N. A. Louis, K. E. Hamilton, T. Kong, and S. P. Colgan, "HIFdependent induction of apical CD55 coordinates epithelial clearance of neutrophils," FASEB Journal, vol. 19, no. 8, pp. 950959, 2005.

[21] U. K. Ewulonu, L. Ravi, and M. E. Medof, "Characterization of the decay-accelerating factor gene promoter region," Proceedings of the National Academy of Sciences of the United States of America, vol. 88, no. 11, pp. 4675-4679, 1991.
[22] D. M. Cauvi, G. Cauvi, and K. M. Pollard, "Constitutive expression of murine decay-accelerating factor 1 is controlled by the transcription factor Spl," Journal of Immunology, vol. 177, no. 6, pp. 3837-3847, 2006.

[23] D. D. Kim and W. C. Song, "Membrane complement regulatory proteins," Clinical Immunology, vol. 118, no. 2-3, pp. 127-136, 2006.

[24] D. M. Cauvi, G. Cauvi, and K. M. Pollard, "Reduced expression of decay-accelerating factor 1 on $\mathrm{CD}^{+} \mathrm{T}$ cells in murine systemic autoimmune disease," Arthritis and Rheumatism, vol. 56, no. 6, pp. 1934-1944, 2007.

[25] T. Miwa, M. A. Maldonado, L. Zhou et al., "Deletion of decayaccelerating factor (CD55) exacerbates autoimmune disease development in MRL/lpr mice," American Journal of Pathology, vol. 161, no. 3, pp. 1077-1086, 2002.

[26] C. B. Toomey, D. M. Cauvi, W.-C. Song, and K. M. Pollard, "Decay-accelerating factor 1 (Dafl) deficiency exacerbates xenobiotic-induced autoimmunity," Immunology, vol. 131, no. 1, pp. 99-106, 2010.

[27] D. M. Cauvi, C. B. Toomey, and K. M. Pollard, "Depletion of complement does not impact initiation of xenobiotic-induced autoimmune disease," Immunology, vol. 135, no. 4, pp. 333-343, 2012.

[28] H. Sogabe, M. Nangaku, Y. Ishibashi et al., "Increased susceptibility of decay-accelerating factor deficient mice to antiglomerular basement membrane glomerulonephritis," Journal of Immunology, vol. 167, no. 5, pp. 2791-2797, 2001.

[29] F. Lin, D. J. Salant, H. Meyerson, S. Emancipator, B. P. Morgan, and M. E. Medof, "Respective roles of decay-accelerating factor and CD59 in circumventing glomerular injury in acute nephrotoxic serum nephritis," Journal of Immunology, vol. 172, no. 4, pp. 2636-2642, 2004.

[30] F. Lin, H. J. Kaminski, B. M. Conti-Fine, W. Wang, C. Richmonds, and M. Edward Medof, "Markedly enhanced susceptibility to experimental autoimmune myasthenia gravis in the absence of decay-accelerating factor protection," Journal of Clinical Investigation, vol. 110, no. 9, pp. 1269-1274, 2002.

[31] D. H. Kono, M. S. Park, A. Szydlik et al., "Resistance to xenobiotic-induced autoimmunity maps to chromosome 1," Journal of Immunology, vol. 167, no. 4, pp. 2396-2403, 2001.

[32] M. H. Owens and B. Bonavida, "Immune functions characteristic of SJL/J mice and their association with age and spontaneous reticulum cell sarcoma," Cancer Research, vol. 36, no. 3, pp. 1077-1083, 1976.

[33] K. Kobayashi, T. Izawa, M. Kuwamura, and J. Yamate, "Comparative gene expression analysis in the skeletal muscles of dysferlin-defcient SJL/J and A/J mice," Journal of Toxicologic Pathology, vol. 24, no. 1, pp. 49-62, 2011.

[34] M. Relle and A. Schwarting, "Role of MHC-linked susceptibility genes in the pathogenesis of human and murine lupus," Clinical and Developmental Immunology, vol. 2012, Article ID 584374, 15 pages, 2012.

[35] P. Hultman, L. J. Bell, S. Enestrom, and K. M. Pollard, "Murine susceptibility to mercury. II. Autoantibody profiles and renal immune deposits in hybrid, backcross, and $\mathrm{H}-2 \mathrm{~d}$ congenic mice," Clinical Immunology and Immunopathology, vol. 68, no. 1, pp. 9-20, 1993.

[36] D. M. Cauvi, P. Hultman, and K. M. Pollard, "Autoimmune models," in Comprehensive Toxicology, C. A. McQueen, Ed., pp. 413-438, Academic Press, Oxford, UK, 2010.

[37] P. Hultman, L. J. Bell, S. Enestrom, and K. M. Pollard, "Murine susceptibility to mercury. I. Autoantibody profiles and systemic 
immune deposits in inbred, congenic, and intra-H-2 recombinant strains," Clinical Immunology and Immunopathology, vol. 65, no. 2, pp. 98-109, 1992.

[38] J. Liu, X. Guan, and X. Ma, "Interferon regulatory factor 1 is an essential and direct transcriptional activator for interferon $\gamma$ induced RANTES/CC15 expression in macrophages," Journal of Biological Chemistry, vol. 280, no. 26, pp. 24347-24355, 2005.

[39] K. M. Pollard, P. Hultman, C. B. Toomey et al., "Definition of IFN- $\gamma$-related pathways critical for chemically-induced systemic autoimmunity," Journal of Autoimmunity, vol. 39, no. 4, pp. 323-331, 2012.

[40] I. Vorechovsky, J. Kralovicova, M. D. Laycock et al., "Short tandem repeat (STR) haplotypes in HLA: an integrated 50$\mathrm{kb}$ STR/linkage disequilibrium/gene map between the RING3 and HLA-B genes and identification of STR haplotype diversification in the class III region," European Journal of Human Genetics, vol. 9, no. 8, pp. 590-598, 2001.

[41] S. A. Tishkoff, E. Dietzsch, W. Speed et al., "Global patterns of linkage disequilibrium at the CD4 locus and modern human origins," Science, vol. 271, no. 5254, pp. 1380-1387, 1996.

[42] O. P. Kristiansen, M. Zamani, J. Johannesen et al., "Linkage and association between a CD4 gene polymorphism and IDDM in Danish IDDM patients," Diabetes, vol. 47, no. 2, pp. 281-283, 1998.

[43] M. Zamani, M. A. Tabatabaiefar, S. Mosayyebi, A. Mashaghi, and P. Mansouri, "Possible association of the CD4 gene polymorphism with vitiligo in an Iranian population: experimental dermatology," Clinical and Experimental Dermatology, vol. 35, no. 5, pp. 521-524, 2010.

[44] K. M. Warpeha, W. Xu, L. Liu et al., "Genotyping and functional analysis of a polymorphic $(\mathrm{CCTTT})(\mathrm{n})$ repeat of $\mathrm{NOS}_{2} \mathrm{~A}$ in diabetic retinopathy," FASEB Journal, vol. 13, no. 13, pp. 18251832, 1999. 


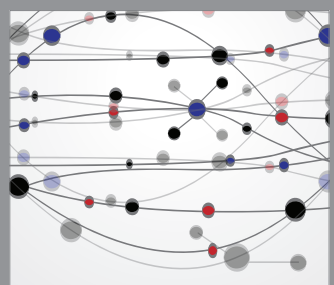

The Scientific World Journal
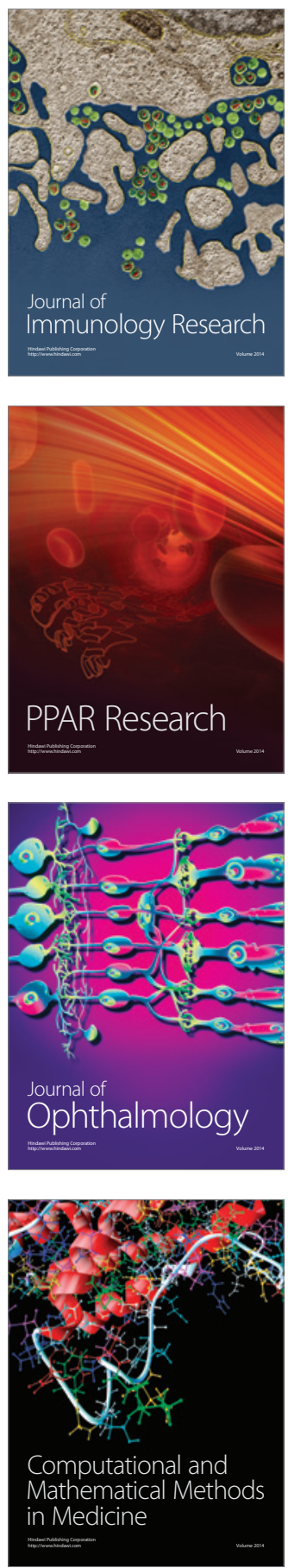

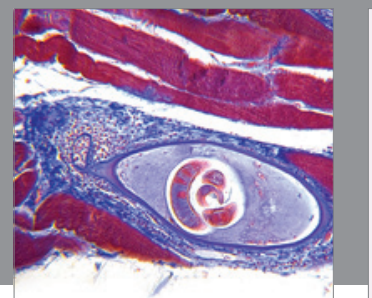

Gastroenterology

Research and Practice
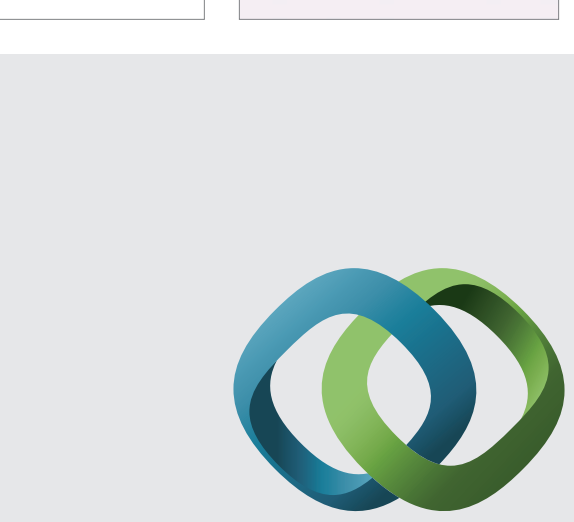

\section{Hindawi}

Submit your manuscripts at

http://www.hindawi.com
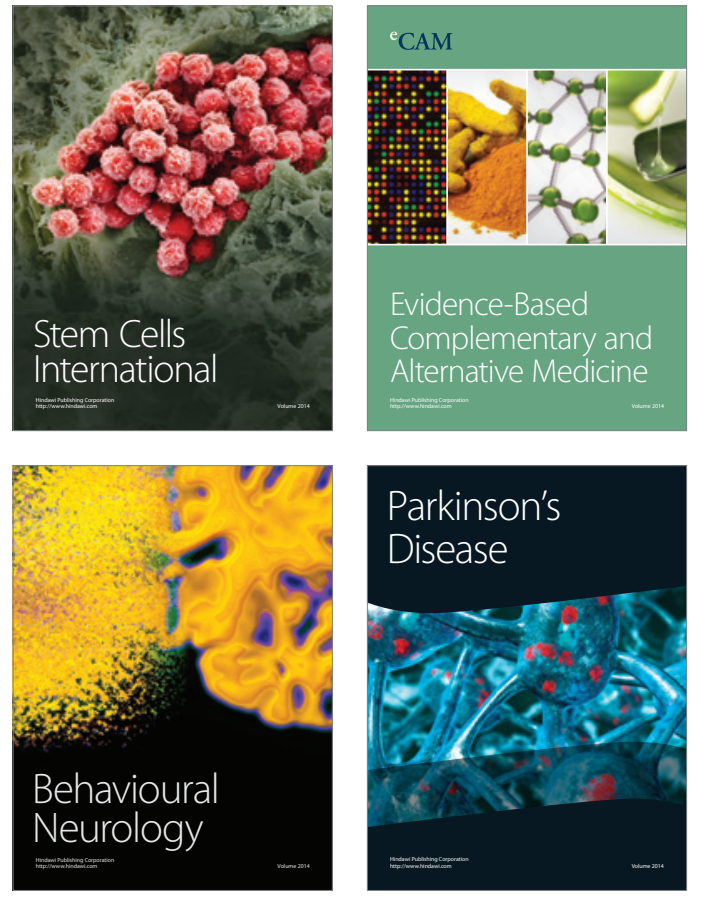
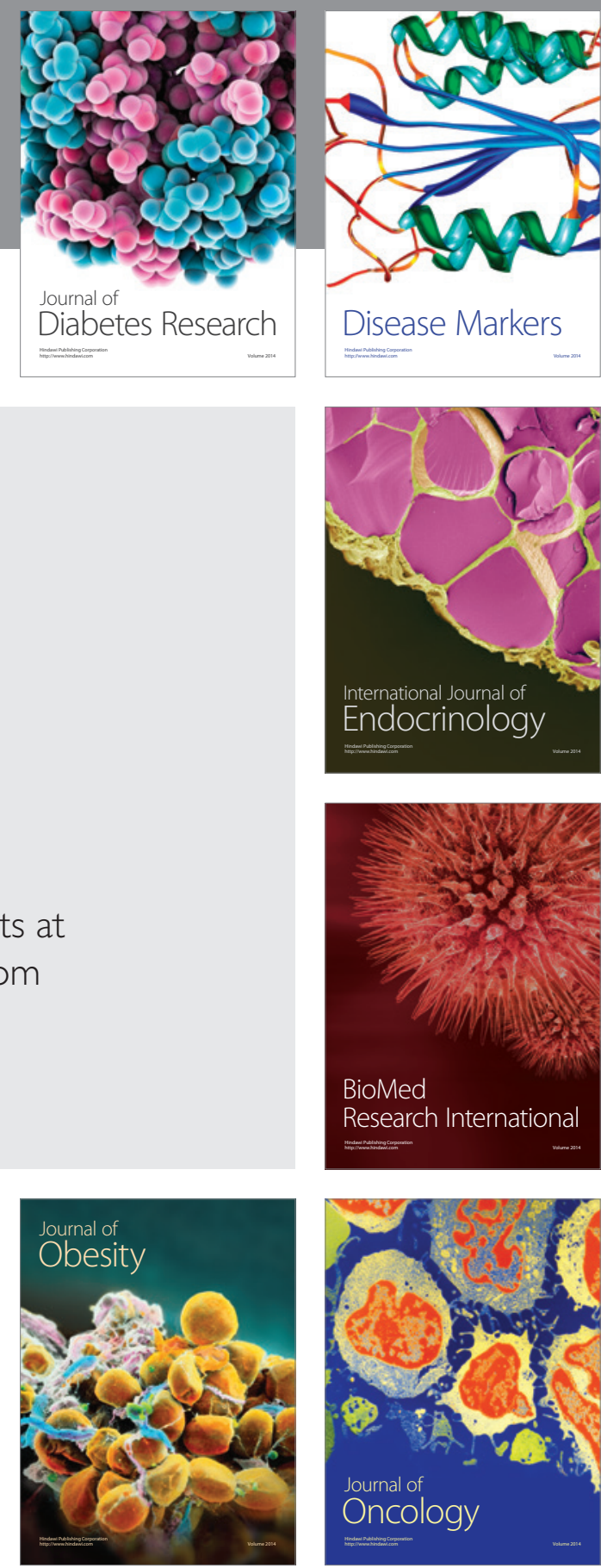

Disease Markers
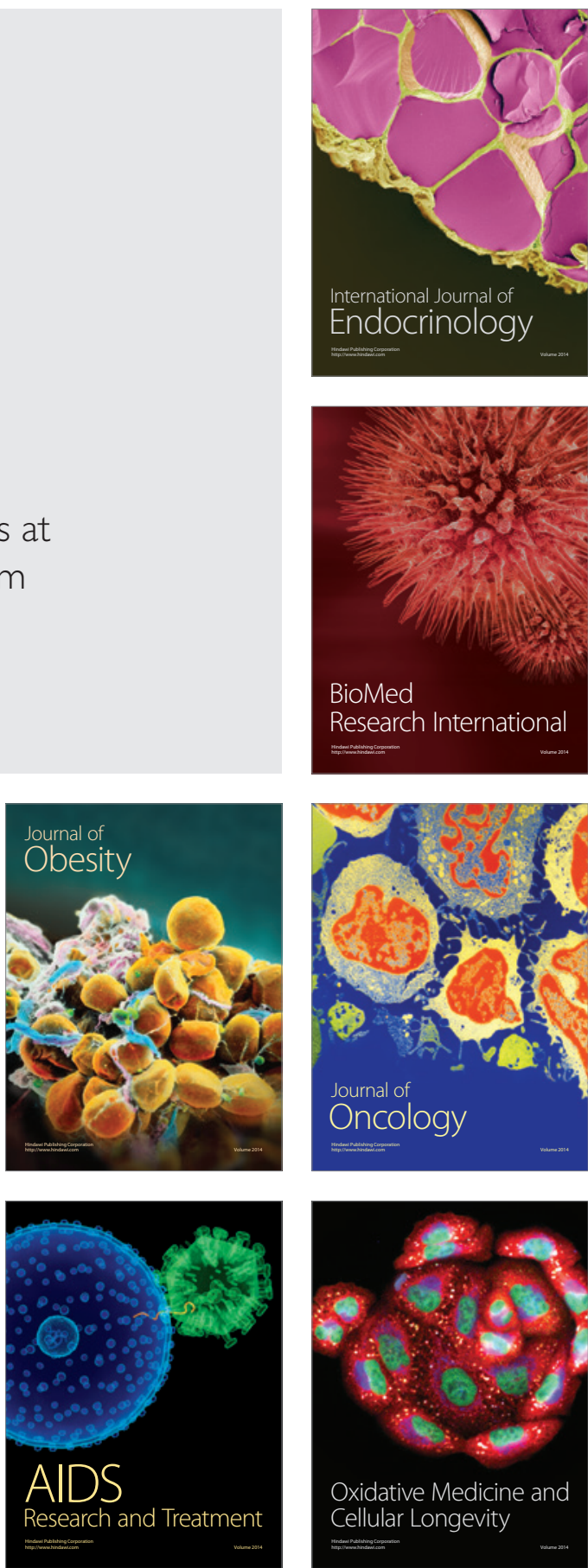